\title{
Assessment of Coagulopathy, Inflammation and LDH Activity in SARS- CoV-2-infected Patients
}

\author{
Ajibola Adisa $^{1 *}$, Moses Akiibinu ${ }^{2}$ \\ ${ }^{1}$ Department of Publich Health, Texila American University, Guyana \\ ${ }^{2}$ Department of Chemistry and Biochemistry, Caleb University, Lagos, Nigeria
}

\begin{abstract}
The patho-physiology of COVID19 is still not clear. This study investigated the status of coagulation, LDH activity, and inflammation in SARS-CoV-2 infected patients. One hundred and thirty-four newly diagnosed COVID19 infected patients (age ranged65-82years) attending Mullingar Regional Hospital, Mullingar, Republic of Ireland, volunteered to participate in this study. They all presented with a pulmonary disorder, pyrexia, vomiting, body pains, etc. SARS-CoV-2 confirmatory test was done with RT-PCR molecular test using Cepheid Genexpert System. The data of another 121 plasma samples of apparently normal, non-COVID19 infected individuals taken before the emergence of COVID19 served as controls. Levels of blood platelets was determined in the participants using Siemen ADVIA 2120 Haematological System, and plasma D-dimer was determined in the participants using Star MaxStago-Automatic Coagulation Analyzer LDH activity, plasma ferritin, and C-reactive protein (CRP) were determined in the participants using Beckman AU680-Chemistry Analyser. SARS-CoV-2 -infected patients showed significantly $(p<0.001)$ higher levels of D-dimer $(1522.95 \pm 1395.45 \mathrm{ng} / \mathrm{ml}), C R P$ $(125.3 \pm 116.4 \mathrm{mg} / \mathrm{l})$, ferritin $(488.5 \pm 514.9 \mathrm{pg} / \mathrm{l})$, and LDH activity $(574.4 \pm 446.7 \mathrm{iu} / \mathrm{l})$ compared to controls $(78.8 \pm 18.1 \mathrm{ng} / \mathrm{ml}, 2.4 \pm 1.7 \mathrm{mg} / \mathrm{l}, 61.3 \pm 58.2 \mathrm{pg} / \mathrm{l}, 304.1 \pm 76.6 \mathrm{iu} / \mathrm{l}$ respectively). The blood platelet count did not show significant $(p>0.05)$ change in the COVID19 patients $\left(252.2 \times 10^{9} \pm 101 x\right.$ $\left.10^{9}\right)$ compared to controls $\left(256.4 \times 10^{9} \pm 63.2 \times 10^{9}\right)$. Elevated LDH activity could indicate tissue breakdown in the SARS-Cov-2 infected patients. Hyper-coagulation and inflammation are imminent in the COVID19 patients. Adjuvant anticoagulant and anti-inflammatory therapies may be useful as part of therapeutic regimen in the SARS-CoV-2 infected patients.
\end{abstract}

Keywords: COVID19, Coagulopathy, CRP and ferritin, LDH.

\section{Introduction}

COVID-19 is a disease caused by severe acute respiratory syndrome coronavirus-2 (SARS-CoV-2). The virus has the ability to spread via natural aerosols from human to human and mother to child during pregnancy [1]. SARS-CoV-2 has been found in stool, aerosols, and blood. Sustained human-to-human transmission through inhalation or contact with infected droplets enhances the pandemicity with an incubation period ranging from 2 to 14 days [2]. The disease is mild (asymptomatic) in most people; and may progress to pneumonia, acute respiratory distress syndrome (ARDS), septic shock, metabolic acidosis, and multi-organ dysfunction in some (usually the elderly and those with co-morbidities) [3]. The virus binds to the angiotensin-converting enzyme-2 molecule, highly expressed on the epithelium of the nasopharyngeal airway, type II pneumocytes of the alveoli, vascular endothelial cells, and the macrophages of the lung tissue of the host [3]. Increased levels of pro-inflammatory cytokines, such as tumour necrosis factor- $\alpha$ (TNF- $\alpha)$ and interleukins (IL), IL-1, and IL-6, have been reported as products of cellular activation in severe SARS-Cov-2 infection $[4,5]$. The 
interplay between blood coagulation, immune cells, and platelets restricts the dissemination of pathogens during infection [6, 7]. The activation of the coagulation system and leucocytes during infection are associated with the release of IL-1, IL-6 which enhances inflammation [4]. Apart from the direct interaction of a typical virus with platelets and other cells, endothelial injury through the interaction of SARS-CoV-2 specifically activates the lectin pathway of complement on the endothelial cell surface [8]. A vast body of literature shows that cellular activation enhances cytokine release and induction of tissue factor (TF) expression on mononuclear cells that subsequently initiates coagulation activation and thrombin generation $[6,9]$.

Transmembrane protein TF secreted by subendothelial cells or induced by pathogenassociated molecular patterns, bacterial lipopolysaccharides, and viral dsRNA can also initiate and enhance the coagulation process [10, 11]. The TF can be complex with the plasma coagulation protease (FVII/FVIIa) to enhance the coagulation process during infection by converting FX to FXa [6, 7]. The FXa then forms the prothrombinase complex with FVa to initiate the conversion of prothrombin to thrombin. The FXa, FVa, and thrombin consequently form a pathway that leads to thrombin-mediated cleavage of fibrinogen to fibrin that is crosslinked by activated FXIII to form a stable clot [4].

Excessive coagulation could initiate the recruitment of leukocytes and enhance inflammation characterized by changes in the plasma levels of acute-phase proteins (APPs) in the infected individuals. Plasma levels of APPs increase (positive APPs) or decrease (negative APPs) in response to inflammation [12]. Activation of the hepatocytes by cytokines such as interleukin-1 (IL-1), interleukin-6 (IL-6), and tumour necrosis factor- $\alpha$ has been reported to play critical roles in the production of the APPs [13].
The consequences of inflammation have been associated with several pathological conditions, including tissue or organ damage. This study was designed to assess the tissue damage by determining the plasma activity of lactate dehydrogenase (LDH), an index of tissue injury. Since coagulopathy, inflammation, and tissue damage have been suspected to be contributing factors in the pathogenesis of COVID19, and this study was designed to assess the levels of coagulopathy, inflammation, and tissue damage in COVID19 patients by determining the plasma levels of D-dimer, C-reactive protein, plasma ferritin, $\mathrm{LDH}$, and blood platelets count in SARS-CoV-2 infected patients.

\section{Materials and Methods}

\section{Materials}

One hundred and thirty-four newly diagnosed COVID19 infected patients presenting directly to Mullingar Regional Hospital, Mullingar, the Republic of Ireland with the pulmonary disorder, pyrexia, vomiting, pains, etc., volunteered to participate in this study. Another 121 plasma samples of apparently normal, non-COVID19 infected individuals taken before the emergence of COVID19 served as controls. Informed consent was obtained from every participant before the commencement of this study. This study was approved by the Institutional Review Board, and ethical approval was obtained from the Texila American University Ethical Committee.

\section{Selection of the Area}

This study was carried people living in Mullingar metropolis and its environs, where Covid 19 prevalence was $2 \%$ at the time the study was conducted. Analyses of samples were carried out at Mullingar Regional Hospital, Mullingar, Republic of Ireland.

\section{Sample Size Determination}

The sample size was determined using the following formula. 


$$
N=\frac{Z \alpha^{2} p q}{d^{2}}
$$

Where:

$\begin{array}{lll}\mathrm{N} & = & \text { required sample size } \\ \mathrm{Z} \alpha / 2 & =\begin{array}{l}\text { Standard deviation at } 95 \% \\ \text { confidence interval }=1.96\end{array} \\ \mathrm{=} & \text { the degree of precision } \\ \mathrm{d} & \text { expected }(3 \%) \\ = & \text { prevalence is } 2 \% \\ \mathrm{p} & 1.96, \mathrm{p}=2 \%, \mathrm{q}=1-\mathrm{p}, \mathrm{d}= \\ \mathrm{Z} & 0.03 \\ = & 1.96 \times 1.96 \times 0.02 \times 0.98= \\ \mathrm{N} & 0.03^{2} \\ & \text { Sample size = } & 83.7\end{array}$

Sampling techniques: A simple random technique was employed to recruit the COVID19 patients for this study.

\section{Data Collection}

Participants were asked to respond to a questionnaire for information about the clinical presentation such as pulmonary disorder, pyrexia, vomiting, body pains after confirmation of COVID19 status. Six milliliters (ml) of venous blood sample were taken from the anticubital vein of every participant. $4 \mathrm{ml}$ was put into lithium heparin was for the determination of LDH activity, ferritin, C-reactive protein and Ddimer. Another $2 \mathrm{ml}$ of blood was put into an ethylene diamine tetra acetic acid (EDTA) bottle for the determination of platelet count. After centrifugation of the sample in a lithium heparin bottle, the plasma was separated and stored at $20^{\circ} \mathrm{C}$ until ready for analysis.

\section{Study Location}

This study was carried out at Mullingar Regional Hospital, Mullingar, Republic of Ireland.

\section{Methods}

For confirmation of COVID19, RT-PCR Molecular Test was carried out using Cepheid Genexpert System. Another 121 apparently normal, non-COVID19 infected individuals whose blood samples have been stored before the emergence of COVID19 served as controls. Levels of blood platelets were determined in the participants using Siemen ADVIA 2120 Haematological System, and plasma D-dimer were determined in the participants using Star Max-Stago-Automatic Coagulation Analyzer LDH activity, plasma ferritin, and C-reactive protein (CRP) were determined in the participants using Beckman AU680-Chemistry Analyser.

\section{Statistical Analysis}

Statistical analyses were performed using Statistical Package for Social Sciences (SPSS) for Windows, version 21.0 (SPSS Inc. Chicago, USA). Data were expressed as Mean \pm SD. Student (T) test was used for comparison of COVID19 patients and controls. The changes were considered as significant when p-values were less than 0.05 .

\section{Results}

As demonstrated in Figs. 1-4, COVID19 patients showed significantly $(\mathrm{p}<0.05)$ higher levels of D-dimer $(1522.95 \pm 1395.45 \mathrm{ng} / \mathrm{ml})$, CRP $\quad(125.3 \pm 116.4 \mathrm{mg} / \mathrm{l}), \quad$ ferritin $(488.5 \pm 514.9 \mathrm{pg} / \mathrm{l}), \quad$ and $\mathrm{LDH}$ activity $(574.4 \pm 446.7 \mathrm{iu} / \mathrm{l})$ compared to controls $(78.8 \pm 18.1 \mathrm{ng} / \mathrm{ml}, \quad 2.4 \pm 1.7 \mathrm{mg} / \mathrm{l}, \quad 61.3 \pm 58.2 \mathrm{pg} / \mathrm{l}$, $304.1 \pm 76.6 \mathrm{iu} / \mathrm{l}$ respectively). The blood platelet count (Fig. 5) did not show significant ( $>0.05)$ change in the COVID19 patients (252.2 $\mathrm{x}$ $\left.10^{9} \pm 101 \times 10^{9}\right)$ compared to controls $(256.4 \times$ $\left.10^{9} \pm 63.2 \times 10^{9}\right)$. 


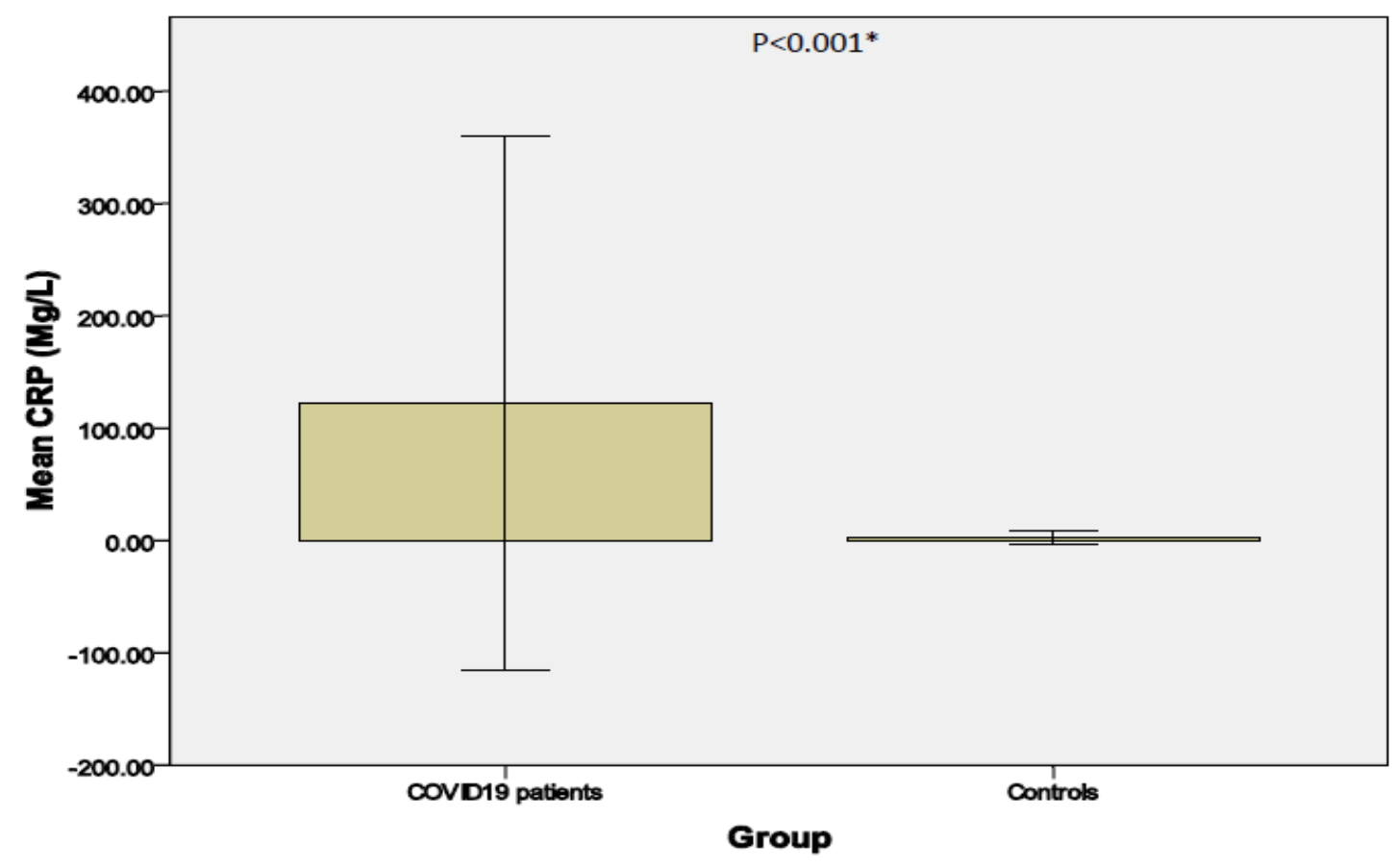

Error Bars: +/- 2 SD

*Significantly different from controls

Figure. 1. Levels of CRP in COVID19 Patients and Controls

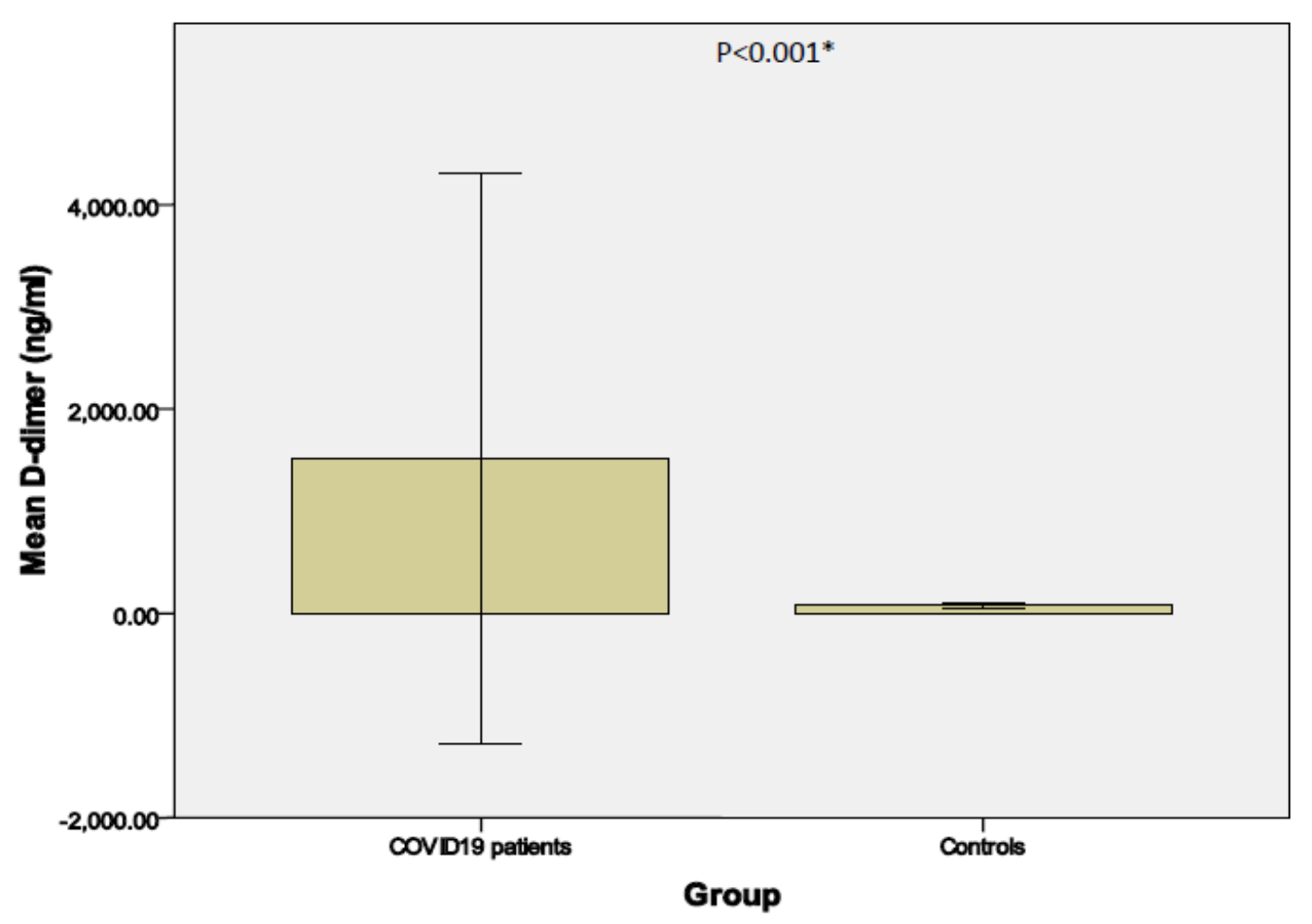

Error Bars: +/- 2 SD

*Significantly different from controls

Figure. 2. Plasma Levels of D-dimer in COVID19-Infected Patients and Controls 


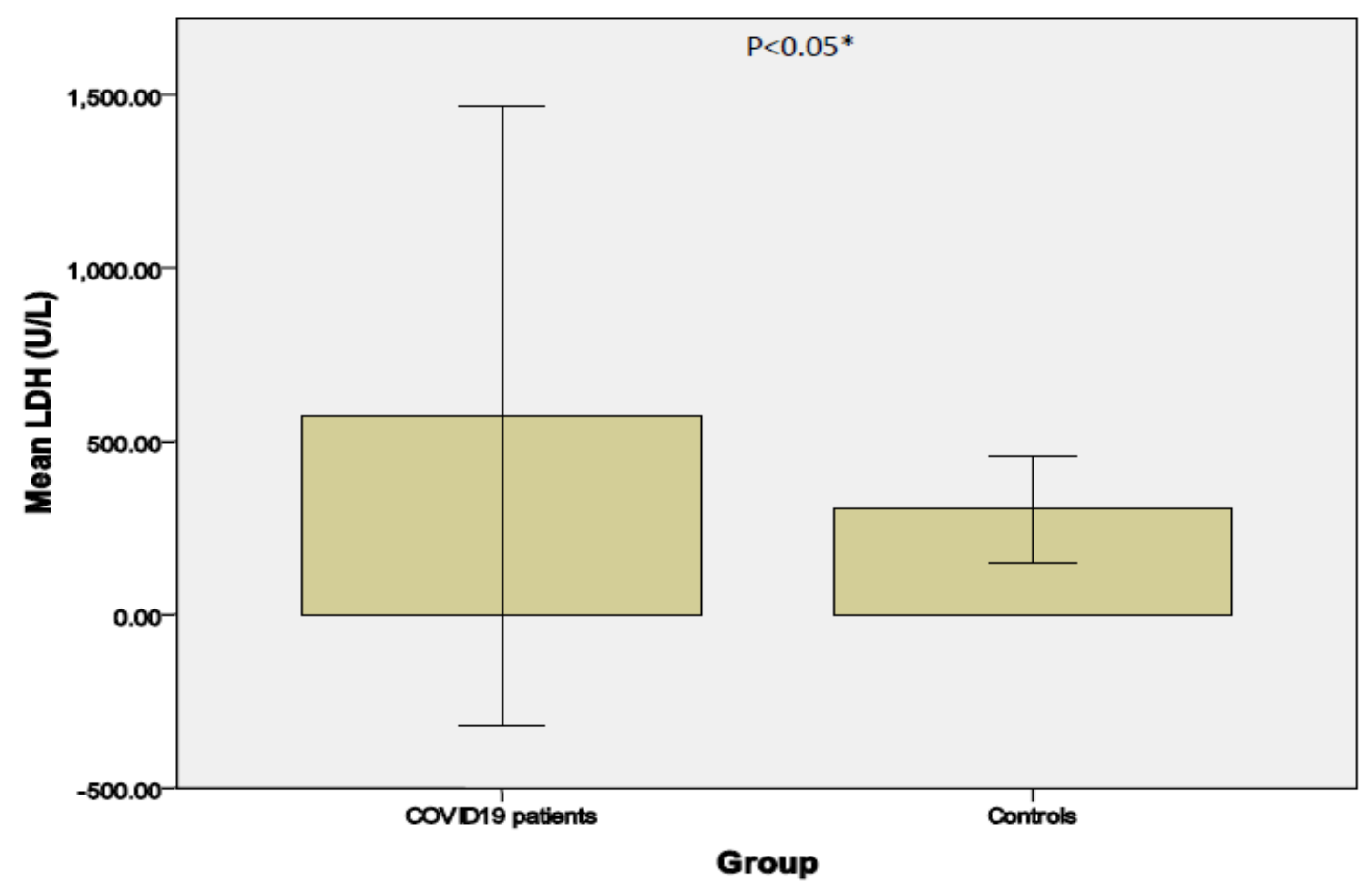

Error Bars: +/- 2 SD

*Significantly different from controls

Figure.3. Plasma Levels of LDH in COVID19-Infected Patients and Controls

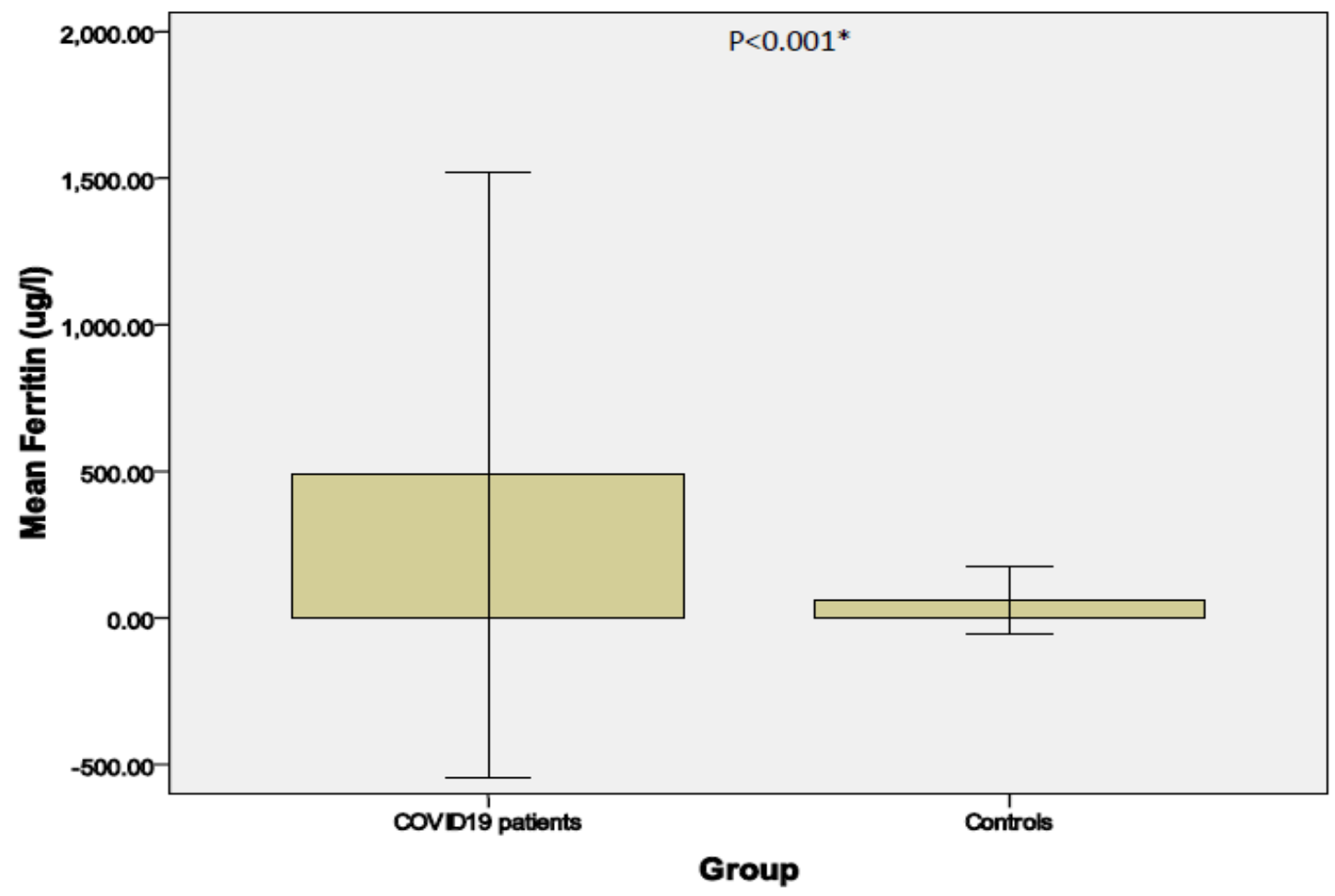

Error Bars: +/- 2 SD

*Significantly different from controls

Figure. 4. Plasma Levels of Ferritin in COVID19-infected Patients and Controls 


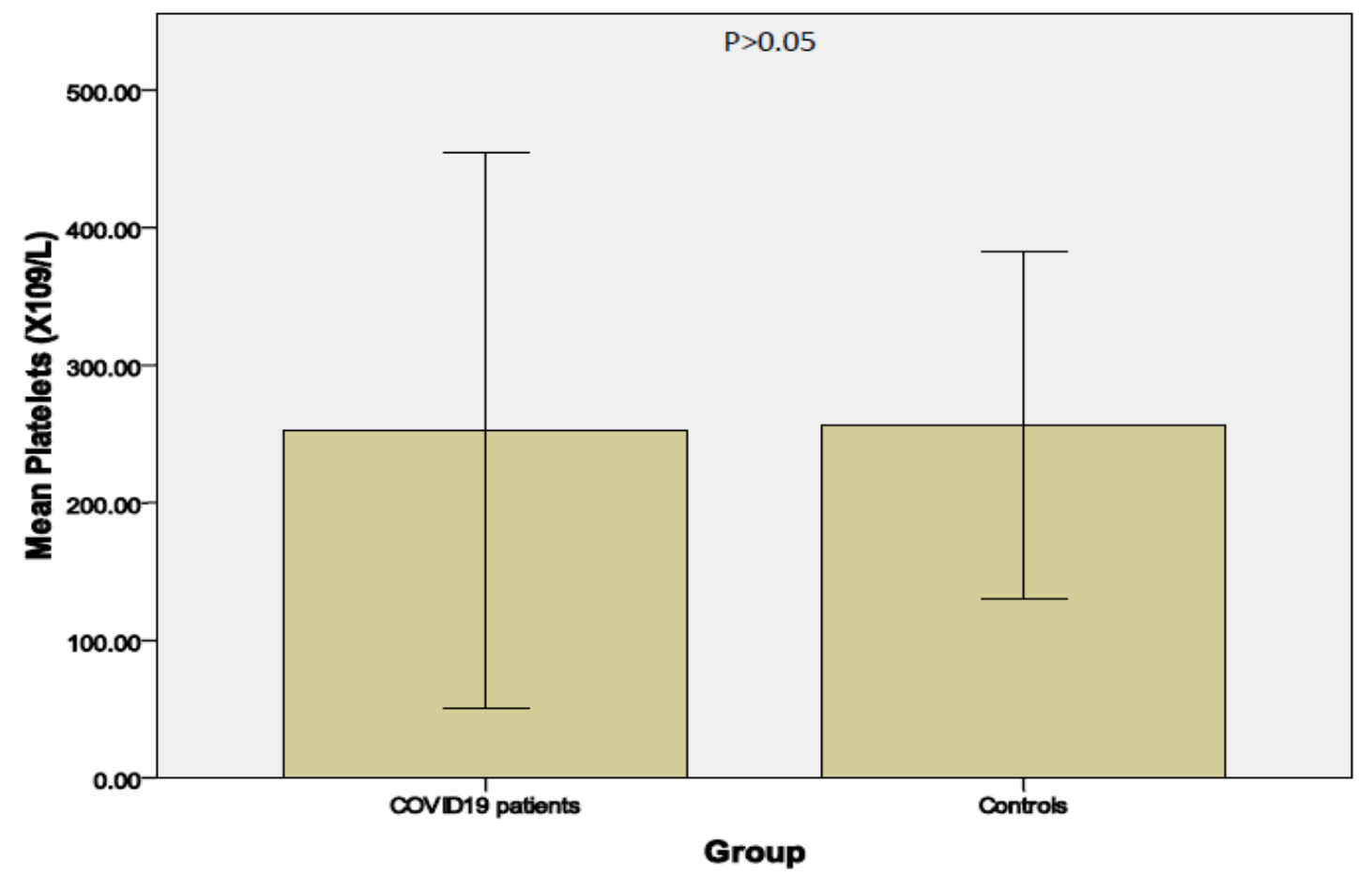

Error Bars: +/- 2 SD

Figure. 5. Levels of Platelets in COVID19-infected Patients and Controls

\section{Discussion}

The pathophysiology of COVID-19 has not been well documented. Available literature shows that respiratory disorder, intra-vascular coagulation, and hypoxia are major consequences of the SARS-Cov-2 infection. Other studies have reported lower levels of CD4+ T-cells and CD8+ T-cells in nearly all the COVID19 patients (14), with significantly higher circulating endothelial cell counts, serum levels of interleukin-6 (IL-6), and interleukin-8 (IL-8) in the COVID19 patients [15]. This present study confirmed the possibility of disseminated intravascular coagulation as proved by a significantly higher level of Ddimer, a product of cross-linked fibrin degradation and an index of hyper-coagulation in our COVID19 patients. The elevated level of D-dimer in this could be due to excessive activation of platelets and inflammation in the COVID19 patients.

This could also be evidence of the excessive intravascular coagulation commonly reported in SARS-CoV-2 infected patients. Previous studies show that under physiological conditions, a balance of coagulation and fibrinolysis maintains the D-dimer generated in the blood of most healthy individuals at a range of $<250$ $\mathrm{ng} / \mathrm{ml}$ [16, 17]. Meanwhile, in this study, a plasma level of $1522.95 \pm 1395.45 \mathrm{ng} / \mathrm{ml}$ was observed in COVID19 patients. A similarly higher level of D-dimer $(2950 \mathrm{ng} / \mathrm{mL})$ has been reported in COVID19 patients by previous workers $[18,19]$. The present finding could be due to the aberration of coagulation and fibrinolysis processes in the COVID19 patients. Since a high degree of fibrin degradation produces an increased level of D-dimer in the SARS-Cov-2 infected patients, this study confirms the clotting complications, such as microvascular thrombi and disseminated intravascular coagulation commonly reported in COVID19 patients by previous studies.

Interleukin-1, interleukin-6 and interferongamma released during cellular activation in COVID19 disease can induce the hepatocytes to produce a large array of acute phase proteins including CRP and ferritin [20]. The changes in 
plasma levels of APPs observed in this study could therefore be due to excessive activation of hepatocytes in response to viremia during SARS-Cov-2 infection [13]. The two APPs (CRP and ferritin) determined in this study are positive acute phase reactants and indices of markers of inflammation that increase in response to infection and trauma. A significantly higher level of CRP in the COVID19 patients recruited for this study could be due to their responses to SARS-CoV-2 infection or inflammation.

The immunological roles of CRP include initiation of opsonization, phagocytosis, and lysis of invading organisms such as bacterial and viruses. It can also activate macrophages, prevents damage to tissues, modulates phagocytic cell functions, enhances the removal of harmful molecules and pathogens, possesses anti-proteolytic activity, and presumably blocks the migration of cells into the lumen of blood vessels, thus preventing the establishment of a generalized systemic inflammation [21]. Therefore, an increased level of CRP in this study might be a protective strategy employed by the system to fight against possible invading pathogens. Our study agrees with the report of previous workers who also observed significantly higher levels of CRP during infections [22, 23]. CRP has therefore been proposed to be an index of severity of COVID19 in emergency cases [24, 25].

A significantly higher level of plasma ferritin observed in our COVID19 patients complements our report of possible inflammation in COVID19 patients. This significant increase in the plasma level of ferritin could be a physiological defense strategy to bind iron and deprive the pathogen from getting enough iron for its metabolic activities. This study corroborates previous reports that serum ferritin concentration increases in response to infections or inflammatory process [22, 23]. This study, therefore, confirm the elevated level of plasma ferritin reported in COVID19 patients by previous researchers [26].
LDH is a cytoplasmic, unilocular enzyme that is present in almost all tissues but at high concentrations in the muscle, liver, and kidney. The function of the enzyme is to catalyze the reversible conversion of lactate to pyruvate with the reduction of NAD+ to NADH and vice versa [27]. The enzyme is also involved in the anaerobic metabolism of glucose when oxygen is absent or in limited supply, a process that could be beneficial in hypoxic COVID19 patients. The activity increases in tissue injury, organ damage, haemolysis, infections, and cancers. High serum LDH activity observed in this study agrees with a previously reported study that presented high LDH activity as a risk factor in younger patients with COVID19 disease [28, 29]. Our study also agrees with other researchers who reported higher levels of LDH in COVID19 patients [15, 25]. The significantly higher LDH activity in our COVID19 patients could be due to tissue or organ damage. Since $\mathrm{LDH}$ is a cytoplasmic enzyme, acute tissue breakdown in the SARS-CoV-2 infected patients could enhance the liberation of the enzyme into the plasma.

Platelet's activation has been implicated in COVID19 pathogenesis, although the functions have not been well defined. A study has reported a significantly lower level of platelets in patients with severe SARS-CoV-2 infection [30]. An early study hypothesized that mild thrombocytopenia with a decreased platelet could be associated with a poor prognosis of COVID19 [31]. Another report demonstrates changes in platelet gene expression and function in COVID-19 patients [32]. The present study did not show any significant change in the platelet status of the COVID19 patients recruited for this study.

Meanwhile, other studies have highlighted that platelet hyperactivity in COVID-19 contributes to the coagulopathy and activation of monocytes, leading to the release of tissue factor, the principal regulator of the coagulation cascade [32, 33]. 


\section{Conclusion}

Increased levels of fibrin degradation product (D-dimer) and CRP are imminent in the COVID19 patients. Elevated LDH activity could indicate tissue breakdown in the SARS-Cov-2 infected patients. Adjuvant anticoagulant and anti-inflammatory therapies may be useful as part of a therapeutic regimen in the SARS-CoV2 infected patients.

\section{References}

[1] Hinojosa-Velasco A, Bobadilla-Montes de Oca VP, García-Sosa LE, Mendoza-Durán JD, PérezMéndez MJ, Eduardo Dávila-González, Dolores G Ramírez-Hernández, Jaime García-Mena, ZárateSegura P, Reyes-Ruiz JM, Bastida-González F., 2020. A Case Report of Newborn Infant with Severe COVID-19 in Mexico: Detection of SARS-CoV-2 in Human Breast Milk and Stool. Int J Infect Dis. 26; S1201-9712(20)30684-6.

DOI: $10.1016 /$ j.ijid.2020.08.055. Online ahead of print.

[2] Guo Y, Qing-Dong Cao, Zhong-Si Hong, YuanYang Tan, Shou-Deng Chen, Hong-Jun Jin, Kai-Sen Tan, De-Yun Wang, Yan Jinn 2020. The origin, transmission and clinical therapies on coronavirus disease 2019 (COVID-19) outbreak - an update on the status. Mil Med Res. 13;7(1):11. doi: 10.1186/s40779-020-00240-0.

[3] Singhal T. 2020. A Review of Coronavirus Disease-2019 (COVID-19). Indian J Pediatr. 87(4):281-286. doi: 10.1007/s12098-020-03263-6. Epub 2020.

[4] Boermeester MA, van Leeuwen PAM, Coyle SM, et al., 1995. Interleukin-1 receptor blockade in patients with sepsis syndrome: evidence that interleukin-1 contributes to the release of interleukin6 , elastase phospholipase A2, and to the activation of the complement, coagulation, and fibrinolytic systems, Arch Surg, vol. 130 (pg. 739-48).

[5] Ur A and Verma K. 2020. Cytokine Storm in Covid19: A Neural Hypothesis ACS Chemical Neuroscience. 11 (13), 1868-1870.

\section{Conflict of Interest}

Author declares there is no conflict of interest.

\section{Acknowledgement}

We appreciate the Mullingar Regional Hospital, Mullingar, the Republic of Ireland, for allowing us to the samples collected from their SARS-CoV-2 infected patients.

[6] Gaertner F, Massberg S., 2016. Blood coagulation in immunothrombosis-At the frontline of intravascular immunity. Semin Immunol. 28: 561- 9. [7] Antoniak S, Nigel Mackman., 2014. Multiple roles of the coagulation protease cascade during virus infection. Bood. 123 (17): 2605-2613. https://doi.org/10.1182/blood-2013-09-526277.

[8] Collard C.D., Vakeva A., Morrissey M.A., Agah A., Rollins S.A., Reenstra W.R., Buras J.A., Meri S., Stahl G.L. 2000. Complement activation after oxidative stress: role of the lectin complement pathway. Am. J. Pathol. 156:1549-1556.

[9] Antoniak S, Owens AP, Baunacke M, et al., 2013. PAR-1 contributes to the innate immune response during viral infection. J Clin Invest. 123:3; 13101322.

[10] Grover SP, Mackman N. 2018. Tissue factor: an essential mediator of hemostasis and trigger of thrombosis. Arterioscler Thromb Vasc Biol. 38: 70925 .

[11]Drake TA, Morrissey JH, Edgington TS. 1989. Selective cellular expression of tissue factor in human tissues. Implications for disorders of hemostasis and thrombosis. Am J Pathol. 134: 1087- 97.

[12] Herpers BL, Endeman H, de Jong BA, de Jongh BM, Grutters JC, Biesma DH, van Velzen-Blad H 2009. "Acute-phase responsiveness of mannosebinding lectin in community-acquired pneumonia is highly dependent upon MBL2 genotypes". Clin Exp Immunol. 156 (3): 488-94. doi:10.1111/j.13652249.2009. 03929.x. PMC 2691978. PMID 19438602.

[13]Feelders RA et al. 1998. Regulation of iron metabolism in the acute phase response: interferon $\mathrm{g}$ tumour necrosis factors a induce hypoferraemia, 
ferritin production, and a decrease in circulating transferrin receptors in cancer patients. European Journal of Clinical Investigation, 28:520-527.

[14]Chen G, Di Wu, Wei Guo, Yong Cao, Da Huang, Hongwu Wang, Tao Wang, Xiaoyun Zhang, Huilong Chen, Haijing Yu, Xiaoping Zhang, Minxia Zhang, Shiji Wu, Jianxin Song, Tao Chen, Meifang Han, Shusheng Li, Xiaoping Luo, Jianping Zhao, Qin Ning., 2020. Clinical and immunological features of severe and moderate coronavirus disease 2019. J Clin Invest. $\quad 1 ; 130(5): 2620-2629 . \quad$ DOI: 10.1172/JCI137244.

[15]Rambaldi A, Giuseppe Gritti, Maria Caterina Micò, Marco Frigeni, Gianmaria Borleri, Anna Salvi, Francesco Landi, Chiara Pavoni, Aurelio Sonzogni, Andrea Gianatti, Francesca Binda, Stefano Fagiuoli, Fabiano Di Marco, Luca Lorini, Giuseppe Remuzzi, Steve Whitaker, Gregory Demopulos. 2020. Endothelial injury and thrombotic microangiopathy in COVID-19: Treatment with the lectin-pathway inhibitor narsoplimab. Immunobiology. 225(6):152001. doi: 10.1016/j.imbio. 152001. Epub 2020 Aug 9.

[16] Pagana KD, Pagana TJ, Pagana TN. 2019. Mosby's Diagnostic \& Laboratory Test Reference. 14th ed. St. Louis, Mo: Elsevier.

[17] Rostami M, Mansouritorghabeh H., 2020. Ddimer level in COVID-19 infection: a systematic review. Expert Rev Hematol. 13(11):1265-1275. DOI: 10.1080/17474086. 2020. 1831383. Epub 2020 Oct 12 .

[18] Al-Samkari H, Rebecca S Karp Leaf, Walter H Dzik, Jonathan C T Carlson, Annemarie E Fogerty, Anem Waheed, Katayoon Goodarzi, Pavan K Bendapudi, Larissa Bornikova, Shruti Gupta, David E Leaf, David J Kuter, Rachel P Rosovsky., 2020. COVID-19 and coagulation: bleeding and thrombotic manifestations of SARS-CoV-2 infection. Blood. 23; 136 (4):489-500. DOI: 10.1182/blood.2020006520.

[19] Bousquet G, Falgarone G, Deutsch D, Derolez S, Lopez-Sublet M, Goudot F, Amari K, Uzunhan Y, Bouchaud O, and Pamoukdjian F. 2020. ADLdependency, D-Dimers, LDH, and absence of anticoagulation are independently associated with one-month mortality in older inpatients with Covid19. Aging (Albany NY). 30; 12(12): 11306-11313.
[20] Watkins LR, Milligan ED, Maier SF., 2003.

Glial proinflammatory cytokines mediate exaggerated pain states: implications for clinical pain. Adv Exp Med Biol. 521:1-21. [PubMed].

[21]Xiang-Hua Y, et al., 2020. severe acute respiratory syndrome and venous thromboembolism in multiple organs. Am. J. respire. Crit. Care Med. $182,436-437$.

[22] Rienhoff HY Jr., 1990. Molecular and cellular biology of serum amyloid A. Molecular Biology and Medicine. 7: 287-298.

[23] Birgegård G, Hällgren R, Killander A, Venge P, Wide. 1979. Serum ferritin during infection. A longitudinal study in renal transplant patients. L.Acta Med Scand. 205 (7):641-5.

[24] Gómez-Pastora J, Weigand M, Kim J, Wu X, Strayer J, Palmer AF, Zborowski M, Yazer M, Chalmers JJ., 2020. Hyperferritinemia in critically ill COVID-19 patients - Is ferritin the product of inflammation or a pathogenic mediator? Clin Chim Acta. 2020 Oct; 509:249-251. DOI: 10.1016/j.cca. 06.033. Epub 2020 Jun 21.

[25] Assandri R, Buscarini E, Canetta C, Scartabellati A, Viganò G, Montanelli A., 2020. Laboratory Biomarkers Predicting COVID-19 Severity in the Emergency Room. Arch Med Res. 51 (6):598-599. DOI: 10.1016/j.arcmed.2020.05.011.

[26] Guan WJ, Ni ZY, Hu Y, et al. 2020. Clinical characteristics of coronavirus disease 2019 in China. N Engl J Med. 382: 1708-20.

[27]Feld J , Douglas Tremblay, Santiago Thibaud, Alaina Kessler, Leonard Naymagon . 2020. Ferritin levels in patients with COVID-19: A poor predictor of mortality and hemophagocytic lymphohistiocytosis. Int J Lab Hematol. 42 (6):773779. DOI: 10.1111/ijlh.13309. Epub 2020 Aug 13.

[28] Schumann G, Bonora R, Ceriotti F, ClercRenaud P, Ferrero CA, Férard G, Franck PF, Gella FJ, Hoelzel W, Jørgensen PJ, Kanno T, Kessner A, Klauke R, Kristiansen N, Lessinger JM, Linsinger TP, Misaki H, Panteghini M, Pauwels J, Schimmel HG, Vialle A, Weidemann G, Siekmann L. 2002. IFCC primary reference procedures for the measurement of catalytic activity concentrations of enzymes at 37 degrees C. Part 3. Reference procedure for the measurement of catalytic concentration of 
lactate dehydrogenase. Clin Chem Lab Med. 40(6):643-8.

[29] Li X, Xu S, Yu M, Wang K, Tao Y, Zhou Y, Shi J, Zhou M, Wu B, Yang Z, Zhang C, Yue J, Zhang Z, Renz H, Liu X, Xie J, Xie M, Zhao J., 2020. Risk factors for severity and mortality in adult COVID-19 inpatients in Wuhan. J Allergy Clin Immunol. 146(1):110-118.

[30]Zhou F, Yu T, Du R, Fan G, Liu Y, Liu Z, Xiang J, Wang Y, Song B, Gu X, Guan L, Wei Y, Li H, Wu X, Xu J, Tu S, Zhang Y, Chen H, Cao B. 2020. Clinical course and risk factors for mortality of adult inpatients with COVID-19 in Wuhan, China: a retrospective cohort study. Lancet. 28; 395(10229):1054-1062. (PubMed).

[31] Tang $N$ et al. 2020. Anticoagulant treatment is associated with decreased mortality in severe coronavirus disease 2019 patients with coagulopathy. J. Thromb. Haemost.

http://doi.org/10.1111/jth.14817.

[32] Yang W., Lee H.W., Hellinga H., Yang J.J., 2002. Structural analysis, identification, and design of calcium-binding sites in proteins. Proteins. 47:344-356.

[33] Manne BK, Denorme F, Middleton EA, et al., 2020. Platelet gene expression and function in patients with COVID-19. Blood. 136 (11):13171329.

[34] Hottz ED, Azevedo-Quintanilha IG, Palhinha L, et al., 2020. Platelet activation and platelet-monocyte aggregate formation trigger tissue factor expression in patients with severe COVID-19. Blood. 136(11):1330-1341. Google Scholar. 